\title{
FOLHAS CAÍDAS OU O JOGO CIFRADO DO AMOR
}

\author{
Mariana Marques de Oliveira ${ }^{1}$
}

RESUMO: O presente trabalho analisa a obra Folhas Caídas, de Almeida Garrett, sob a perspectiva do jogo cifrado da linguagem, tendo como foco o discurso amoroso. Discutese de que maneira Garrett constrói o jogo de simulação da linguagem que tem como intuito a visibilidade da obra e de si ao mesmo tempo em que traz um registro de discurso amoroso ao modo garrettiano. Tal discurso põe em coexistência os paradoxos do sentimento amoroso, que necessita do corpo para concretizar o que existe como sentimento. Escondido pela linguagem cifrada, esse discurso seduz o leitor a fim de envolvê-lo e instigá-lo a desvendar o cunho erótico da poesia. Desse modo, busca-se investigar a Advertência da obra como o início da encenação da linguagem cifrada e alguns caminhos de leitura dos poemas em que o erotismo pode ser desvelado pelo leitor de Folhas Caídas.

PALAVRAS-CHAVE: Almeida Garrett, Folhas Caídas, Discurso amoroso, Erotismo.

\section{FOLHAS CAÍDAS OR THE CIPHERED LOVE GAME}

ABSTRACT: This work analyzes Folhas Caídas, by Almeida Garrett, under the perspective of a ciphered language game, focusing on the lover's discourse. We discuss in which manner Garrett constructs a game of language simulation that aims at increasing this work and the author's visibility and also shows a lover's discourse record in a typical Garrett style. That discourse brings into coexistence the paradoxes of the love feeling, that needs the body to materialize what exists only as a feeling. Hidden by the cyphered language, this discourse seduces the reader in order to enfold and instigate him to unveil the erotic nature of the poem. Thereby, we pursue the investigation of the initial, Advertencia, as the beginning of the staging of the cypher language and also interpretations of the poems in which the eroticism can be revealed by the reader of Folhas Caidas.

KEYWORDS: Almeida Garrett, Folhas Caidas, Lover's Discourse, Eroticism.

\footnotetext{
${ }^{1}$ Mestranda do Programa de Pós-Graduação em Letras Vernáculas (Literaturas Portuguesa e Africanas) da Universidade Federal do Rio de Janeiro. Bolsista da Fundação de Amparo à Pesquisa do Estado do Amazonas (Fapeam).
} 
Escrevo mais para mim do que para ti.

(Cartas Portuguesas)

O meu amor é 'um órgão sexual de uma sensibilidade espantosa'

(BARTHES, Fragmentos de um discurso amoroso)

O professor Helder Macedo inicia seu artigo "Garrett no Romantismo Europeu" de modo categórico: "Almeida Garrett nunca é um escritor evidente" (2007, p. 25). A assertiva torna-se notável quando se observa que Garrett simula sê-lo constantemente em sua obra. Simulação essa trabalhada tão astutamente em Folhas Caídas, que colaborou para que a crítica tardasse a desvincular a biografia de Garrett à obra. Tanto a escolha do amor como tema, que de tão íntimo e por cuja experiência parece se ater à especificidade de cada indivíduo, quanto a simulação do "desejo biográfico de auto-representação" (ALVES, 1999 , p. 152) tendem a conduzir ao caminho de leitura para o foco da confluência entre poesia e vida. É do manejo da linguagem, construído pelo autor de Viagens na Minha Terra, que essa evidência nasce com intuito de seduzir e envolver o leitor.

A estratégia é articulada de tal modo que se torna necessário nos determos já na Advertência de Folhas Caídas, visto que se configura como a abertura de um palco para a simulação das aproximações da vida e da obra. ${ }^{2}$ O paratexto ${ }^{3}$ inicia do seguinte modo: "Antes que venha o Inverno e disperse ao vento essas folhas de poesia que por aí caíram, vamos escolher uma ou outra que valha a pena conversar" (FC, p. 2). Instala-se um momento de mudança, em que o inverno se aproxima para levar as "folhas caídas" do outono, isto é, simula-se um movimento de quase salvamento desses poemas e que o discurso, pela ironia, parece demonstrar um quase desdém de publicar "uma ou outra que valha a pena conversar". Todavia, se levarmos em conta que Garrett as escolheu para publicação, é porque as valoriza para tal. A justificativa pela subjetividade para escolha dessas "folhas" colabora com o jogo da intimidade simulada: "gosto mais deles do que de nenhuns outros que fizesse. Porquê? É impossível dizê-lo, mas é verdade" (ibidem). Do mesmo modo, Folhas Caídas é destacada pelo autor do resto de sua obra: "Os cantos que formam esta pequena colecção pertencem todos a uma época de vida íntima e recolhida que nada tem com as minhas outras colecções" (ibidem). É dito que a produção da obra se deu em um momento íntimo, apontando-se para o interior da "alma" do poeta e seus sentimentos. Destacaríamos também o termo "todos", que tem como intuito dar um

\footnotetext{
${ }^{2}$ Faz-se necessário destacar que a Advertência estava presente na obra desde a primeira edição, o que nos indica que já fazia parte do projeto do autor a construção do jogo da simulação, para o qual a Advertência tem importância fundamental.

${ }^{3}$ Maria Theresa Abelha Alves atenta para a valorização dada por Garrett ao paratexto: "Em prefácio datado de 14 de dezembro de 1844, parecia reconhecer a importância das margens do texto, e o papel que elas representam na conquista do novo público leitor arregimentado pelo Romantismo, ao se pronunciar assim: 'Estamos na era da renascença dos prefácios, das dedicatórias, e avisos ao leitor.' Parecia saber que os paratextos encerram mistérios a desvendar, recortes a fazer para a compreensão das obras em que se encontram." (1999, p. 142)

${ }^{4}$ As próximas identificações da obra serão referenciadas por FC e o número da página.
} 
caráter globalizante a Folhas Caídas e indicar para uma única motivação, um único tema. Quanto mais aproxima as justificativas da obra à sua subjetividade, ${ }^{5}$ mais fortalece o palco de encenação de um discurso amoroso que muito mais do que querer se basear na própria experiência do autor, busca, de modo cifrado, fixar um discurso amoroso caracterizado por conjugar as sensações paradoxais do amor.

Paralelamente, encena-se um ato de justificativa e defesa: "parece-me que o melhor e mais recto juiz que pode ter um escritor é ele próprio, quando o não cega o amorpróprio. Eu sei que tenho os olhos abertos, ao menos agora” (p. 3), o que potencializa a atenção para o tom íntimo das palavras que se esperam, por dramatizar que algo que está indo a público só poderá ser entendido mais "inteiramente" pelo próprio autor. Descortina-se um jogo de esconder/revelar construído de tal forma que coloca o leitor em desafio ao tentar desvendar o que há de tão "íntimo" e, por isso, difícil de se entender. Estrategicamente, o autor ironiza seus sentimentos de modo que o menosprezo a esse íntimo trazido a público sirva de reforço para o jogo de aproximação simulada de vida e obra: "Folhas Caídas representam o estado de alma do poeta nas variadas, incertas e vacilantes oscilações do espírito" (p. 3). Está aí a chave para o leitor seguir o caminho de decifração do discurso subjetivo da obra, a qual não tratará de sentimentos nobres da alma humana - que muitas vezes se detêm no espaço da idealização -, mas da coexistência de sentimentos controversos que o ser humano enfrenta na vida, e em especial, nas experiências amorosas. Isto é, na Advertência, o autor indica que descerá o amor à terra ao falar de um sentimento amoroso que perturba, que causa conflito, que desestabiliza.

Em introdução a Folhas Caídas da editora Portugália, em 1955, José Gomes Ferreira, de modo enérgico, contraria-se com a relação limitadora entre vida e obra do autor e nos reforça esse amor que Garrrett simula na Advertência: "nem me venham, por favor, com essa treta da paixão pela viscondessa da Luz. Garrett amava-se a si mesmo, mais nada. Eis o segredo. (Tão simples!). Amava-se a si mesmo." (apud SILVEIRA, 1999, p. 89). O desdém que simula o autor na Advertência - que chega a duvidar se seus poemas são "bons ou ruins" (FC, p. 2) - esconde a vaidade e o projeto arquitetado para a escrita de Folhas Caídas. O discurso erótico da obra, portanto, é realização do trabalho com a linguagem construída de modo cifrado por Garrett. Georges Ifrah caracteriza as cifras como "suportes do sonho, do fantástico, da especulação metafísica, materiais de construção da literatura, instrumentos de sondagem do futuro incerto ou, pelo menos, do desejo de predizer, as cifras são uma substância poética" (IFRAH apud CHEVALIER \& GHEERBRANT, 1998, p. 240). Se a ironia desperta o leitor para abrir os olhos para "o caminho do desvio para o qual a sedução das palavras o leva" (cf. PERRONE-MOISÉS, 1990), a cifra dá a chave para que o leitor procure destrancar os (des)caminhos dessa linguagem.

Maria Theresa Abelha Alves defende que o paratexto é estratégia de sedução de linguagem em Garrett: "procura fornecer-lhe [ao leitor] as ferramentas adequadas para desvendar, os segredos do texto a fim de torná-lo mais nítido, num fecundo exercício de sedução e aliciamento" (1999, p. 144). Observa-se que a abertura da obra fisga o leitor à

${ }^{5}$ Pela voz de Gustavo Rubim: “A aparência de intimidade é um simulacro de verdade espontânea” (1999, p. 202). 
medida que, pela modéstia dissimulada, instiga-o a querer entender esses versos que trarão a maior causa da instabilidade emocional: o amor. Ao simular essa profunda subjetividade das poesias de Folhas Caídas, a Advertência - que, mais que um paratexto, já faz parte da construção da temática de Folhas Caídas - configura-se como um pacto da leitura ao envolver o leitor com essa subjetividade, desafiando-o a desvendar o que esses versos trazem e colocando-o no lugar de "mortal", numa posição de obediência à suposta imortalidade do autor: "Deixai-o [o poeta] passar, porque ele vai onde vós não ides; vai, ainda que zombeis dele, que o calunieis, que o assassineis. Vai, porque é espírito e vós sois matéria" (p. 3). É nesse tom imperativo que o autor assume já ter consciência do escândalo ${ }^{6}$ de sua obra e, ao se denominar imortal, demonstra a audácia que apenas o poeta tem de "ir aonde os leitores não vão", isto é, de ver o que os leitores não veem - ou não querem ver - e que este ser superior, dito de modo irônico e também narcísico, é espírito e que nós, leitores, somos matéria, ou seja, somos de carne, chave essa central para entender o discurso amoroso que se esconderá por trás dos versos dramatizados de Garrett. É na Advertência, portanto, que Garrett exige um leitor obediente, mas o instiga ao mesmo tempo a ser "ativo" na leitura.

A escolha do tema "amor" corrobora com a estratégia de aproximação entre vida e obra, uma vez que simula o "caráter involuntário - e fatal - das confissões amorosas" (MOURÃO-FERREIRA apud RUBIM, 1999, p. 202). O tema "amor" parece tanto dar-se apenas no espontâneo quanto primar pela singularidade - buscando indicar que não haveria característica comum quando se falasse dele -, o que também ajuda a simulação garrettiana. Em consonância com Ortega Y Gasset, que defende ser o sentimento amoroso o assunto mais fecundo em nossa vida íntima por atrair outros assuntos (1960, p. 71), a abrangência do tema o torna mais passível de singularização pelo indivíduo em sua experiência. Ao lado do referencial da experiência, que se caracteriza pela especificidade do indivíduo, é possível citar as referências estéticas em que a linguagem tem o discurso sobre o amor como mote. Jorge de Sena posiciona Folhas Caídas na tradição de um discurso amoroso:

na história da poesia portuguesa [...] esse livro marca, pela maior parte de seus poemas, uma posição comparável à Bernadim, da lírica menor de Camões e de Gonzaga. [...] E terá de esperar-se pelo nosso tempo para que em António Botto ou José Régio, o desejo físico seja poeticamente expresso ou utilizado com semelhante franqueza (1981, p. 116).

$\mathrm{O}$ autor de Metamorfoses, ao mesmo tempo em que indica uma tradição do discurso amoroso, termina por louvar o caráter estético original de Folhas Caídas. Também Jacinto Prado Coelho posiciona a obra na esteira da tradição ao dizer que Garrett acompanha José

\footnotetext{
${ }^{6}$ Para além do escândalo que a obra causou devido à associação dos versos à viscondessa da Luz, Matildes D. Santos aponta outra justificativa: "Talvez toda essa reflexão sobre o amor tenha incomodado a conservadora sociedade portuguesa do século XIX, ávida por ler sobre amores sublimes, vividos por seres excepcionais, de almas nobres e elevadas.” (1999, p. 161).

${ }^{7}$ Em "O discurso dissimulador das Folhas Caídas", Márcia Gobbi cita Brait para tratar das exigências do leitor co-participante de Folhas Caídas, e que, poderíamos expandir para o leitor de Garrett como um todo: "[o leitor] deve ser capaz de transcender a literalidade da 'mensagem' dada para vislumbrar, justamente que o enunciador deixa, as significações ao mesmo tempo sugeridas e escondidas por esse espaço significante". (1999, p. 128)
} 
Anastácio e de Bocage ao trazer o "amor como pecado, pelo drama de viver repartido entre os nobres anseios da alma e as 'vis' solicitações da carne" (s/d, p. 140). Nesse jogo entre passado e futuro da crítica, a poesia de Folhas Caídas parece aproximar-se mais de uma extrema dramatização do desejo físico motivado pelo sentimento amoroso do que uma indecisão polarizada entre matéria e espírito.

Sob a visão do amor enquanto experiência, entre "Ignoto deo" e "Adeus" pareceria haver uma quebra, um descontínuo que indicaria a polarização entre o amor conceitual e o amor carnal (cf. COELHO, s/d, \& MOURÃO-FERREIRA apud RUBIM, 1999). Entretanto, se atentarmos à Advertência mais uma vez, veremos que nela consta um sobreaviso no que refere ao poema-dedicatória da obra: "no Ignoto deo não imaginem alguma divindade meio velada com cendal transparente [...]. O meu deus desconhecido é realmente aquele misteriosos, oculto e não definido sentimento de alma que a leva às aspirações de uma felicidade ideal” (FC, p. 3). Na abertura da obra então já se declara que o deus de Folhas Caídas é diferente do divino muito preconizado, indicando que o deus dessa obra, isto é, quem comanda esse discurso, é o "sentimento de alma". Assim, um caminho é delineado: o do sentimento que desperta desejos para o alcance da felicidade. Partindo de uma leitura sob o olhar da experiência, o poema-dedicatória passa ao tom irônico, uma vez que termina com as seguintes palavras: "Fica este livro - confissão sincera / Da alma que a Ti voou e em Ti só “spera" (p. 6). Por essa perspectiva, o poema seguinte, “Adeus", não entra como um choque e virada de polo amoroso, uma vez que nele nos deparamos com uma teatralização de um fim, ou seja, a cena de uma experiência, a das mais marcantes e dolorosas do amor. E põe-se o caminho terreno que seguirá: "Este que amar-te não sabe / Porque é só terra - e não cabe / Nele uma ideia dos céus” (p. 9). No poema seguinte, "Quando eu sonhava", lemos:

Quando era vaga,/ Um ideia, um pensamento, / Um raio de estrela incerto / no imenso firmamento, / Uma quimera, um vão sonho / Eu sonhava - mas vivia: / Prazer não sabia o que era, / Mas dor, não a conhecia... (p. 10).

Nesses versos, associa-se a idealização do amor a uma não vivência - "mas dor, não na conhecia" - em contraposição à ideia de que o amor existe verdadeiramente no momento de sua realização, experimentação, na carne, na dor e no prazer do gozo, e que urge passar pelo concreto para existir. O filósofo Ortega Y Gasset, em seu Estudos sobre o amor, corrobora com a experiência tátil vista nos versos em questão:

O amor é obra de arte maior, magnífica operação das almas e dos corpos. Mas é indubitável que para produzir-se necessita apoiar-se numa porção de processos mecânicos, automáticos e sem espiritualidade nenhuma. (1960, p. 106).

Um olhar romântico tenderia a nos induzir a dizer que haveria, na afirmação de Ortega y Gasset, uma diminuição da caracterização do amor, contudo, nada mais é que a

${ }^{8}$ É necessário destacar que recorte do trabalho abarca os poemas pertencentes somente ao Livro Primeiro da obra Folhas Caidas. 
constatação de que o amor só se concretiza nas relações corpóreas. É por esse amor, distante da transcendência divina e próximo à experiência, que o poeta nos mostra o quão plena pode ser essa realização do homem. Não se fala de negação de sentimento, mas de reconhecimento daquilo de que o amor precisa para se realizar. Em Aquela Noite, é possível observar algumas caracterizações desse amor:

\author{
Frio o sarcasmo saía \\ De meus lábios descorados, \\ E sem dó e sem pudor \\ A todos falei de amor... \\ Do amor bruto, degradante, \\ Que no seio palpitante, \\ Na espádua nua se acende... \\ Amor lascivo que ofende, \\ Que faz corar...Elas riam \\ E oh que não, não se ofendiam! (p. 13).
}

Ao não se ofenderem, percebe-se que se está num espaço em que é permitido falar desse amor realizado, "que faz corar", ato que, pelos adjetivos usados, acontece não por causar intimidação, mas por ser ardente. O “seio", elemento altamente erótico, é metonímia do corpo, que palpita por ser tomado pelo amor "bruto, degradante". É a partir desse contexto que se lerá um dos poemas em que o desejo toma a cena. É possível observar uma busca pela desconstrução da ideia do amor conceitual e do que se associa à palavra "amor" e a seus cognatos, muitas vezes aliado à serenidade, à perfeição, criado com o intuito de apaziguar o impulso de desejo humano.

Não te amo, quero-te: o amar vem d'alma.

E eu n'alma - tenho a calma,

A calma - do jazigo,

Ai! não te amo, não.

$[\ldots]$

E quero-se, e não te amo, que é forçado,

De mau feitiço azado

Este indigno furor.

Mas oh! não te amo, não.

$\mathrm{E}$ infame sou, porque te quero; e tanto

Que de mim tenho espanto,

De ti medo e terror...

Mas amar!...não te amo, não. (p. 38)

Há uma busca pela dessacralização do amor, quando o desejo do homem ultrapassa o sentimento amoroso - que geralmente vem associado à quietude, a determinado apaziguamento, a certo ato contemplativo - e se mostra ativo, ávido, excitado, permitindo que o "quero-te" imponha certa urgência de vivência, de experimentação. Também se observa um combate à tradição que envolve o amor, quando é adjetivado de "forçado", pois se critica a tradição de um discurso que, no próprio espaço da literatura, cultiva o amor 
distanciado de sua materialização, em estado puro, muitas vezes divinizado, como nos afirma Ortega Y Gasset:

Os poetas, desde sempre, o ornaram e puliram com seus instrumentos cosméticos, dotando-o de uma estranha realidade abstrata, a tal ponto que, antes de senti-lo, o conhecemos, o estimamos e nos propomos a exercitálo, como uma arte ou um ofício. (1960, p. 83)

Ao desmistificar o conceito cristalizado do amor, Folhas Caídas mostra que no centro da experiência amorosa está o desejo, sentimento autêntico do homem, o mais sincero possível, quando passa pela "situação de extrema atenção ao outro" (ORTEGA Y GASSET, op. cit., p. 102) - o que, mais popularmente, chamamos de relacionamento. É diante da tradição em torno do amor "puro" que o autor já sabe que será julgado como infame, mas que não o faz negar sua vontade, pois termina reiterando: "Mas amar!... não te amo, não". Em Folhas Caídas, então, o amor desperta o desejo, o que não inibe o primeiro sentimento e o que humaniza o amante de Folhas Caidas. O querer, despertado pelo sentimento amoroso, é a busca de possuir, é a busca pela corporificação do amor. A assertiva "não te amo" não clama pela negação do sentimento amoroso, mas evidencia a necessidade de realização do amor, espaço onde, de fato, o amor se sacia. Outro momento em que, pelo questionamento, atenta-se à crítica à cristalização do amor, agora (des)ligado ao divino, está em “Anjo és".

Anjo és. Mas que anjo és tu?

Em tua fronte anuviada

Não vejo a c'roa nevada

Das alvas rosas do céu.

Em teu seio ardente e nu

Não vejo ondear o véu

Com que o sôfrego pudor

Vela os mistérios d'amor.

Teus olhos têm negra a cor,

Cor de noite sem estrela;

A chama é vivaz e é bela,

Mas luz não têm. - Que anjo és tu?

Em nome de quem vieste?

Paz ou guerra me trouxeste

De Jeová ou Belzebu? (p. 43)

Vemos uma mulher despida física e metaforicamente. Joga-se de modo cifrado novamente com o modelo pré-concebido de mulher angelical, dotada de alvura, coroa e olhos claros. No modo com que o texto desconstrói - pelo jogo da dúvida - a mulher idealizada no momento em que a vê com olhos mais terrenos a aguçar seus profundos desejos, mais uma vez o caráter humano é evidenciado como fundamental para despertar o sentimento amoroso. Novamente opostos cristalizados culturalmente são questionados. O que promove de apaziguamento ou desassossego no amante é posto em questão: "Paz ou 
guerra me trouxeste / De Jeová ou Belzebu?”. O endeusamento se dá no sentido dos prazeres inigualáveis que a mulher pode proporcionar ao homem. E por despertar o que de maior tesura há no amante, ele termina por perguntar: “Anjo és tu ou és mulher?”. Seria anjo se estabilizasse, se fosse estéril, se trouxesse o céu. Mas ela fez o inverso, no cume da experiência do amor: "Não responder - e em teus braços / Com frenéticos abraços / Me tens apertado, estreito! Isto que me cai no peito/ Que foi?...Lágrima? - Escaldou-me...”. Os mistérios que teria o anjo passa a ter a mulher pelo jogo da linguagem, que, de modo cifrado, é audacioso e alcança o cômico. A lágrima, que seria o máximo que o anjo exprimiria pela emoção, humaniza a mulher ao se tornar gozo.

Enquanto experiência, o gozo é o auge da expressão e de experiência do amor. Para além do sentido de "desfrutar de" - sentindo comum do vocábulo na cultura portuguesa -, o texto garrettiano possibilita a leitura pelo cunho erótico, aproximando o gozar de seu caráter mais carnal. Incontido no falar dissimulado, o gozo emerge e torna-se também tema central da experiência amorosa de Folbas Caídas. E esse cume erótico é o que mais se quer "sentir" em Folhas Caidas:

Se estou contente, querida, / Com esta imensa ternura / De que me enche o teu amor? / - Não. Ai! não; falta-me a vida, / Sucumbe-me a alma à ventura: / $\mathrm{O}$ excesso do gozo é dor. /[...] É que não há ser bastante / Para este gozar sem fim / Que me inunda o coração. / Tremo dele, e delirante / Sinto que se exaure em mim / Ou a vida - ou a razão. (“Gozo e dor", p. 24)

O modo tenro como se inicia o poema é traído por um grande estremecimento que se observa a partir do quarto verso, de modo que a ternura se revela como prazer. Por trás da linguagem delicada, encontra-se o amor ardente. A descrição de um momento de gozo o tremor, o delírio e o triunfo da emoção sobre a razão - busca abarcar uma sensação. Segundo Octavio Paz,

a linguagem - som que emite sentido, traço material que denota idéias corpóreas - é capaz de dar nome ao mais fugaz e evanescente: a sensação; por sua vez, o erotismo não é mera sexualidade animal - é cerimônia, representação. O erotismo é sexualidade transfigurada: metáfora. A imaginação é o agente que move o ato erótico e o poético. (1994, p. 12)

A linguagem poética de Folhas Caídas abarca essa capacidade de que fala Paz, tocar a sensibilidade erótica humana assim como despertar a imaginação do leitor, por meio da cifra, para os (des)caminhos eróticos da linguagem. Em Folhas Caídas, o amor compreende justamente essa "sexualidade transfigurada", por envolver um sentimento que desperta os desejos mais vorazes e ao mesmo tempo mais delicados e frágeis do ser humano. Percebese que o ser transcende - já que "não há ser bastante" - a partir da vivência humana e não mais da busca à transcendência divina. $O$ excesso da experiência não se desloca para nenhuma sensação ideal, em essência, elevada, mas para outra, intrinsecamente humana: "O excesso do gozo é dor". O termo "coração" pode também assumir, no jogo erótico da linguagem garrettiana, um significado amplo: "Para este gozar sem fim / Que me inunda o coração" nos remete a outro espaço, o espaço do gozo no corpo. O coração, pela linguagem cifrada, move-se do símbolo de significação pura do amor para o órgão sexual 
masculino. Ao inundar o coração, percebe-se, também metaforicamente, que é no objeto fálico que o homem é envolvido pelo sentimento, e que é desse espaço que o amor pulsa. Em "Os cinco sentidos", toda a louvação à amada é construída a partir do caráter sinestésico do amante e esses sentidos terminam em culminância no corpo, quando nele estão: A ti! ai, a ti só os meus sentidos / Todos num confundidos, / Sentem, ouvem, respiram; / Em ti, por ti deliram. / Em ti a minha sorte,/ A minha vida em ti; / E quanto venha a morte, / Será morrer por ti. (p. 34) Nessa estrofe, última do poema, observa-se novamente um ápice: os sentidos, que antes foram vistos separadamente, misturam-se, mas o que se quer destacar é onde essa comunhão acontece: "em ti”. Os sentidos são simultaneamente despertados pela realização do amor, como afirma Lucia Ribeiro:

"Os cinco sentidos" simulam verdadeira relação sexual, embora, é claro, não descrevam cenas de sexo explícito. Carregado de erotismo, o poema sugere nas três primeiras estrofes, pela enumeração dos sentidos da visão, da audição e do olfato, a atração. Em seguida, as sensações de gosto e tato aludem às carícias preliminares trocadas entre ao amantes, até atingirem o orgasmo na última estrofe. (1999, p. 112)

O momento do gozo aparece, como observado, de maneira cifrada quando, ao declarar "A minha vida em ti”, lembra-nos de que é necessário que o corpo esteja dentro do outro para a concretização do amor, isto é, a relação sexual é o momento de desordenação dos sentidos. Paralelamente, a expressão "a minha vida" torna-se o que de mais vivo dele pode nela ficar: o seu gozo.

A experiência que se observa nos versos de Folhas Caídas também é de um eu que desfruta o momento do gozo, explora o momento de modo a se perceber a satisfação singular não apenas do prazer, mas também o de se ter prazer. Em "Cascais", em que se relembram o auge e o declínio de um amor nesse espaço deserto, propício à consagração amorosa, o foco é para o que o amante sente: "Ai! sim foi a tragos largos, / Longos, fundos, que a bebi / Do prazer a taça: - amargos / Depois... depois os senti / Os travos que ela deixou... / Mas como eu ninguém gozou." (p. 38). A sensação aguda do gozo, mesmo que causado por ela, é, portanto, único e intransferível. Em relação à (in)trasitividade do amor, Ortega Y Gasset pontua:

O amor (a paixão sexual, com ou sem superlativos líricos), substantivo de um verbo eminentemente transitivo, é em certo sentido o mais intransitivo, o mais hermético de todos, pois começa e acaba no sujeito, porque de sua alma se alimenta e não tem mais vida que o próprio sujeito lhe dá. (1960, p. 146)

Por mais que a relação sexual seja a dois, o seu ápice, para cada um dos que a compõe, é singular. Isso indica que ao se falar do eu que geme, que treme, que goza, a obra fala de uma experiência que ao mesmo tempo em que é dividida, é única, que ao mesmo tempo em que é a dois, quer falar de um. O reflexo que se faz do amado nos versos termina por compor um retrato do ato de saciar o amante. É semelhante ao que se lê no poema "Não te amo", anteriormente citado: "Dar, e tomar / Do outro ser a que se há dado". Fala-se da exclusividade do prazer, do delírio, do tremor, e tal exclusividade da 
sensação pertence e se detém ao $e u$ da linguagem, pois ao outro se conhece por intermédio desse $e$, e é assim que se configura o jogo da linguagem de Folhas Caídas. Esse jogo também releva um eu que ama amar, também expresso em verso: "Este inferno de amar como eu amo!". A conjunção "como" nos permite decifrar o cunho erótico do verso, nesse caso de dois modos: se a denominarmos conjunção conformativa, centraliza-se a experiência erótica do amor que se caracteriza como inferno; se lermos o "como" sob o valor de intensidade, declara-se ter prazer no ato de amar. De modo semelhante à maneira pela qual se questiona termos ligados à divindade em "Anjo és", o termo "inferno", que aparece no verso acima, pode também colocar em xeque esse significado, uma vez que tanto indica sofrimento, dor, instabilidade, quanto calor, fogo, chama - ambos os significados presentes nos versos, porém distanciados novamente do caráter divino, que associa inferno à morte, visto que se trata, no poema, da experiência vivida: "Mas nessa hora a viver comecei".

Saltou-nos aos olhos a interjeição "ai", vista no verso citado acima, uma vez que aparece como constante recurso na obra. Queremos discutir o efeito que esse "ai", ao aparecer constantemente na primeira parte da obra em questão, pode causar. É sabido que essa interjeição carrega o significado tanto de dor como de prazer. No contexto de Folhas Caídas, é possível ampliar o valor dela para um "ai" declarado também em ato de prazer: um suspiro, um grito, um modo de expressar o prazer, que, nessa obra, também vem a ser dor. Na linguagem erótica de Folhas Caídas, o "ai" significa o estremecimento do gozo, a dor do prazer, a expressão natural do que a sensação pode provocar. Poderíamos então chegar a cogitar um momento de leitura desses versos, talvez momento em que a leitura do "ai" poderia mais revelar o prazer. Falar-se-ia de outro momento delicado: o da leitura em voz alta de versos. Contudo, no caso de Folhas Caídas, novamente haveria uma dessacralização, por ser necessário demonstrar pela leitura o erotismo pungente dos versos e lê-los sob o contexto do gozo e da dor. Desse modo, a experiência não é somente amorosa, mas também estética, quando ao leitor é dada a oportunidade de adentrar em seus versos e na leitura também se deleitar. Pelo jogo do erotismo, cria-se o espaço do prazer do leitor, como nos assevera Roland Barthes:

Se leio com prazer esta frase, esta história ou esta palavra, é porque foram escritas no prazer (este prazer não está em contradição com as queixas do escritor). Mas e o contrário? Escrever no prazer me assegura a mim, escritor o prazer de meu leitor? De modo algum. Esse leitor, é mister que eu o procure (que eu o drague), sem saber onde ele está. Um espaço de fruição fica então criado. Não é a pessoa do outro que me é necessária, é o espaço: a possibilidade de uma dialética do desejo, de uma imprevisão do desfrute: que os dados não estejam lançados, que haja um jogo. $(1987$, p. $7-8)$

O jogo do simulacro garrettiano equilibra o tema do arrebatador desejo sexual com a afetividade. $\mathrm{O}$ poeta põe opostos em coexistência quando mostra experiências nas quais $\mathrm{O}$ sentimento amoroso convive com a sua realização corpórea, unindo amor e sexo. A obra capta o leitor pela narração constante de experiências que envolvem o íntimo, mas que necessitam do exterior para atingir a plenitude. É pelo jogo cifrado que nos deparamos 
com o espaço do jogo erótico da linguagem, o qual se mostra como mais uma estratégia garrettiana, pois o leitor é envolvido pela própria identificação com o seu íntimo, e ao ler a experiência de outro, sente tocado a si. Por trás das profundezas íntimas dos versos, há também um gozo autoral que se vangloria por construir o jogo erótico ao leitor. Bataille caracteriza o erotismo como um movimento reflexivo, como se pode observar em Las lágrimas de Eros: "El erotismo implica la busqueda deliberada de um fin que culmina em si mismo: el pracer" (2007). O discurso que choca, mas que envolve, pois se aproxima daquele com o que o leitor se identifica: o espaço mais recôndito do homem, do desejo natural, muitas vezes incontrolável. Portanto, por mais íntimo que alcançar o jogo erótico de Folhas Caídas, mais universal se torna.

O escândalo de Folhas Caídas não se justifica somente pela relação que logo se fez com a vida do autor, mas do assunto de que trata, por ser tabu. Todavia, é também um dos assuntos que mais interessam o ser humano: o prazer amoroso. E novamente aí está o "gozo" do autor em estabelecer o jogo erótico da linguagem. Por trás do discurso subjetivo, revelou-se um discurso amoroso a modo Garrett - "nunca evidente", que parece ser característica de escritores que, como o autor, são atemporais e inclassificáveis. No lugar de divagações de tom confessional dos sentimentos, o jogo textual de Folhas Caídas traz a premência de se falar sobre o amor distante da idealização, por fazer da urgência do corpo a sua maior necessidade para a concretização, e abarcar em si um sentimento que se encerra no instável estável. ${ }^{9}$ Por trás de uma subjetividade que se autorrepresenta confidencial, está o registro do discurso amoroso que Garrett quis deixar no intuito de se imortalizar - como disse na Advertência -, o que vai ao encontro às epígrafes deste artigo: a primeira alude às Cartas Portuguesas: "escrevo mais para mim do que para ti”, que, já no século XVII, traziam o tom reflexivo do discurso amoroso e cuja caracterização se identifica com a assertiva de Barthes: "o meu amor é "um órgão sexual de uma sensibilidade espantosa" (2010, p. 206), que, por associar, metaforicamente, o verbete 'amor' - ou seja, a essência, o sentimento ao órgão sexual - isto é, a parte carnal, o desejo - apresenta-se como síntese do discurso amoroso garrettiano em Folhas Caídas.

\section{BIBLIOGRAFIA}

ALCOFORADO, Mariana. Cartas Portuguesas. Prefácio e trad. Eugénio de Andrade. Lisboa: Assírio \& Alvim, 1993.

ALVES, Maria Theresa Abelha. Almeida Garrett: o texto, o intertexto e as margens do texto na representação do escritor. In: Scripta, Belo Horizonte, v. 3, n. 5, p. 142-154, $2^{\circ}$ sem. 1999.

BARTHES, Roland. Fragmentos de um discurso amoroso. Trad. Isabel Pascoal. Lisboa: Edições 70, 2010.

\footnotetext{
${ }^{9}$ Lucia Ribeiro contribui também com a caracterização do discurso amoroso por Garrett em Folhas Caídas: "Para a concepção garrettiana, o sentimento em repouso e sem conflito não é amor, porque este, para ser verdadeiro, tem de provocar sensações contraditórias e indefiníveis, mantendo o amante inseguro e confuso entre ódio, paixão, desejo, repulsa, despeito, enleio, ciúme, prazer, sofrimento, dor, dúvida, receio, impulso, agressividade, passividade, remorso, falsidade, perdão, sinceridade, confiança, desconfiança.” (1999, p. 112)
} 
- O prazer do texto. São Paulo: Perspectiva, 1987.

BATAILLE, Georges. Las lágrimas de Eros. Trad. David Fernández. Barcelona: Tusquets Editores, 1997.

CHEVALIER, J. e GHEERBRANT, A. Dicionário de Simbolos (mitos, sonhos, costumes, gestos, formas, figuras, cores, números). 12. ed. Rio de Janeiro: José Olympio, 1998.

COELHO, Jacinto do Prado. O amor e o tempo nas 'Folhas Caídas' de Garrett. In: Problemática da História Literária. 2. Ed. Lisboa: Ática, s/d. p. 139-144.

. Garrett e os seus mitos. In: Problemática da História Literária. 2. Ed. Lisboa: Ática, s/d. p. 151-157.

GARRETT, Almeida. Folhas Caídas. In: Biblioteca Digital Camões (site do Instituto

Camões). Disponível em: <http://cvc.institutocamoes.pt/component/docman/doc_download/1050-folhas-caidas.html>. Acesso em: 20 de ago. 2011.

GOBBI, Márcia Valéria Zamboni. O discurso dissimulador das Folhas Caídas. In: Scripta, Belo Horizonte, v. 3, n. 5, p. 125-133, 20 sem. 1999.

MACEDO, Helder. Garrett no Romantismo Europeu. In: Trintas Leituras. Lisboa: Editorial Presença, 2006. p. 25-34.

PAZ, Octavio. A dupla chama: amor e erotismo. Trad. Wladyr Dupont. São Paulo: Siciliano, 1994.

PERRONE-MOISES, Leyla. Flores da escrivaninha: ensaios. São Paulo: Companhia das Letras, 1990.

ORTEGA Y GASSET, José. Estudos sobre o amor. Rio de Janeiro: Livro Ibero-Americano, 1960.

RIBEIRO, Lucia. Almeida Garrett: poesia e autobiografia. In: Scripta, Belo Horizonte, v. 3, n. 5, p. 108-114, $2^{\circ}$ sem. 1999.

RUBIM, Gustavo. As armadilhas da confidência. In: Colóquio/Letras, Lisboa, Ensaio, no. 153/154, p. 201-208, jul. 1999.

SANTOS, Matildes Demetrio. Amar por cartas - este inferno de amar. In: Scripta, Belo Horizonte, v. 3, n. 5, p. 155-167, 2 sem. 1999.

SENA, Jorge de Sena. Garrett, criador poético. In: Estudos de Literatura Portuguesa-I. Lisboa: Edições 70, 1981. p. 107-111.

SILVEIRA, Jorge Fernandes da. Rosas cruzadas - a poesia de Almeida Garrett. In: Scripta, Belo Horizonte, v. 3, n. 5, p. 89-101, 2º sem. 1999. 